\title{
Analysis of long-lived radionuclides produced by proton irradiation in lead targets $-\gamma$-measurements
}

\author{
By T. Lorenz ${ }^{1,2}$, Y. Dai ${ }^{3}$ and D. Schumann ${ }^{1, *}$ \\ ${ }^{1}$ Laboratory for Radio- and Environmental Chemistry, Paul Scherrer Institut, 5232 Villigen PSI, Switzerland \\ 2 University of Bern, 3012 Bern, Switzerland \\ ${ }^{3}$ Laboratory for Nuclear Materials, Paul Scherrer Institut, 5232 Villigen PSI, Switzerland
}

(Received November 26, 2012; accepted in revised form March 12, 2013)

(Published online September 16, 2013)

\section{Spallation neutron source / Radionuclide inventory / \\ Lead target / $\gamma$-Spectroscopy / Radiochemistry}

Summary. The presented work aims at a radiochemical analysis of the radionuclide inventory of a solid lead target irradiated with high energetic protons in the spallation neutron facility SINQ at Paul Scherrer Institute. Lead samples from the vicinity of the beam entry have been extracted. A detailed $\gamma$-analysis shows the radial distribution of selected radionuclides relative to the incoming beam. The concentrations of these nuclides are evaluated in dependence on the proton beam profile.

\section{Introduction}

A cascade of three proton accelerators, with a $590 \mathrm{MeV}$ magnetic-sector field ring cyclotron at high beam current up to $2.2 \mathrm{~mA}$ as final stage, is driving the world's most powerful continuous spallation neutron source (SINQ) at Paul Scherrer Institute [1,2]. The proton beam is fully stopped in a solid-state lead target producing spallation neutrons. These isotropically emitted neutrons are thermalized in a liquid deuterium tank and guided to dedicated beam lines for various scientific applications. Usually, such a target is used for 2 years and, consequently, becomes highly activated during irradiation due to the high intensity of the beam. Hence, the precise knowledge of the radionuclide inventory is mandatory for the purposes of safety risk assessment, decommissioning, and disposal of such highly activated targets.

The isotope inventory of accelerator waste induced by high-energetic protons differs strongly from the inventory of nuclear reactors. Elements from nearly the whole periodic table with a lower mass number than the target element lead are produced by spallation, fragmentation, and high-energy fission processes [3]. Moreover, species like ${ }^{206-209} \mathrm{Bi}$, with larger atomic number than the target element are formed as well, due to compound nucleus reaction of stable lead isotopes ${ }^{204,206-208} \mathrm{~Pb}$. Next to such primary reactions, also reactions of lead with high energetic secondary particles like helium and tritium, as well as $(p, x n)$ reactions of in-situ generated long-lived ${ }^{207} \mathrm{Bi}(31.55 \mathrm{yr})$ and ${ }^{209} \mathrm{Bi}\left(1.9 \times 10^{19} \mathrm{yr}\right)$,

\footnotetext{
*Author for correspondence (E-mail: dorothea.schumann@psi.ch).
}

leading to products like ${ }^{208-210} \mathrm{Po}$ with a higher atom number up to $Z+2$ ( $Z=$ target atomic number) may have an impact on the final radionuclide spectrum. Theoretical predictions of the residue isotope inventory are difficult, due to the complexity of the involved nuclear reactions. Experimental data are urgently needed in order to benchmark and improve theoretical high-energy models and calculation codes, such as MCNPX, FLUKA and INCL4/ABLA.

Our investigations focus in first order on isotopes with half-lives longer than several months, considering issues of disposal and final storage as well as radiological accident scenarios. Unfortunately, short-lived radionuclides, mainly important for accident scenarios, are not detectable in the target material after several years of cooling time. Therefore, they cannot be considered in this work. Some important radionuclides will be investigated based on the following selection criteria:

1. Radionuclides with high energetic photons and half-lives up to 500 years have to be considered, due to their major contribution to the total activity and dose rate of the radioactive waste, even after several years of cooling time. These candidates are ${ }^{207} \mathrm{Bi}(31.55 \mathrm{yr}),{ }^{194} \mathrm{Hg} /{ }^{194} \mathrm{Au}$ (520 yr), ${ }^{173} \mathrm{Lu}(1.37 \mathrm{yr}),{ }^{172} \mathrm{Hf} /{ }^{172} \mathrm{Lu}(1.87 \mathrm{yr}),{ }^{133} \mathrm{Ba}$ (10.5 yr), ${ }^{125} \mathrm{Sb}(2.77 \mathrm{yr}),{ }^{102 \mathrm{~m}} \mathrm{Rh}(2.9 \mathrm{yr}),{ }^{101} \mathrm{Rh}$ (3.3 yr), ${ }^{60} \mathrm{Co}(5.27 \mathrm{yr})$.

2. Isotopes decaying by $\alpha$-emission $\left({ }^{208} \mathrm{Po}(2.898 \mathrm{yr}),{ }^{209} \mathrm{Po}\right.$ $(102 \mathrm{yr}),{ }^{210} \mathrm{Po}(138 \mathrm{~d})$ and $\left.{ }^{148} \mathrm{Gd}(74.6 \mathrm{yr})\right)$ are of essential importance, due to their radiotoxic effects on human health $[4,5]$.

3. Attention will be paid to radionuclides of volatile species like ${ }^{129} \mathrm{I}\left(1.57 \times 10^{7} \mathrm{yr}\right),{ }^{194} \mathrm{Hg} /{ }^{194} \mathrm{Au}(520 \mathrm{yr})$ and especially ${ }^{208-210} \mathrm{Po}$, due to their high inhalation probability in case of radiological accident scenarios. Investigations of their evaporation behaviour from lead based spallation target materials are ongoing [6-8].

4. As a spinoff, high power spallation targets are a potential source of rare and very long-lived isotopes. Some candidates like ${ }^{44} \mathrm{Ti}(60.40 \mathrm{yr}),{ }^{26} \mathrm{Al}\left(7.16 \times 10^{5} \mathrm{yr}\right)$ and ${ }^{53} \mathrm{Mn}$ $\left(3.7 \times 10^{6} \mathrm{yr}\right)$ are of essential importance for nuclear astrophysics, due to their involvement in different stages of the stellar evolution. Other cosmogenic radionuclides like ${ }^{154} \mathrm{Dy}\left(3.0 \times 10^{6} \mathrm{yr}\right),{ }^{146} \mathrm{Sm}\left(1.03 \times 10^{8} \mathrm{yr}\right),{ }^{150} \mathrm{Gd}$ 
$\left(1.8 \times 10^{6} \mathrm{yr}\right)$ and ${ }^{182} \mathrm{Hf}\left(9.0 \times 10^{6} \mathrm{yr}\right)$ are related to element synthesis in the solar system. The research in this scientific field requires the knowledge on nuclear data investigating the production and destruction paths of these long-lived isotopes, and thus, depends on the availability of a sufficient and suitable target material. Unfortunately, these materials are lacking in many cases. To improve this situation, an initiative called ERAWAST (Exotic Radionuclides from Accelerator Waste for Science and Technology) was started at PSI several years ago aimed to use accelerator waste as source for the isolation of interesting radionuclides $[9,10]$. First results on the half-life and neutron capture cross section of ${ }^{60} \mathrm{Fe}$ were achieved using an irradiated copper beam dump [11, 12]. The use of suitable samples from irradiated lead would broaden the spectrum of available material up to higher masses.

The main goal of the project is the complete description of the radionuclide inventory in a solid lead target of the SINQ facility and its distribution radial to the beam injection direction. Federal authorities call for those experimental data in order to assess risks related to the storage of this kind of radioactive waste in final or intermediate repositories. Furthermore, the results are useful to benchmark the codes in this mass region and thus will contribute to the investigation of existing target systems [13] and to the design of future target concepts like the MYRRHA [14] project, based on lead and lead-bismuth as target materials. Additionally, the results will help to identify suitable samples serving as sources for exotic radionuclides for the ERAWAST project.

In this work, first results on the determination of the radionuclide inventory and its radial distribution at beam entry using $\gamma$-spectrometry will be presented. We will give an overview on the PSI target strategy, followed by a detailed sample description. A comparison of the production rates of radionuclides and a correlation to the beam intensity will be pursued.

\section{SINQ target designs}

The solid-state target at SINQ can be described as an array of rods, filled with spallation material arranged perpendicular to the proton beam direction (see Fig. 1). The beam is fully stopped within this target. A double-walled $\mathrm{AlMg}_{3}$ shell with a hemispherical beam entrance window contains the target. Both, the beam-entrance window and the rods are cooled by two loops of heavy water $\left(\mathrm{D}_{2} \mathrm{O}\right)$ in counter current flow.

The primary design (Mark II 1997-1999 [1]) consisted of pure Zircaloy rods mounted in a hexagonal zircaloy frame, equipped with thermocouples and test specimen rods [15, 16]. The produced spallation neutron flux was not satisfying, so that in 2000, a new generation of target design (Mark III, 2000-2005 [17]) was established. A tetragonal frame was equipped with rods of stainless steel SS316L tubes filled with the heavy element lead. The gain of neutron flux was increased by a factor of 1.5 , due to the larger mass number of the spallation material. Three targets of this type had been operated. During this period investigations on irradiation effects on different kinds of materials have been performed in the framework of the SINQ Target Irradiation Program [18]. In 2006 a first test with a liquid metal target containing Lead-Bismuth-Eutectic (LBE) was performed in the Megawatt Pilot Experiment MEGAPIE [19]. For the first time, it could be shown that a liquid metal target can be successfully operated during a time period of several months with a gain of the neutron flux of about $80 \%$. However, due to high costs caused by the necessary complete re-design of the spallation neutron facility in case of a routinely used liquid metal target, it was decided to work on further improvements of the solid lead target.

The following solid-state target design combined lead rods with Zircaloy cladding (Mark IV, 2007-2008 [20]). An improvement of the neutron fluxes of about $10 \%$ was achieved by substituting the strongly neutron absorbing stainless steel SS316L with Zircaloy, which has a much lower absorption cross-section. This kind of configuration has been investigated with the test rods implemented in the previous target operated 2004-2005 [20]. The current target composition (Mark V, since 2009 [21]) with perpendicular arranged rods in a cylindrical framework gave a plus of $60 \%$ concerning the neutron yield. Since 1999, including a $75 \%$ proton beam intensity upgrade, the neutron flux improved more than $300 \%$ up to $1 \times 10^{13}$ neutrons $/ \mathrm{cm}^{2} / \mathrm{s} / \mathrm{mA}$ at the Neutron Activation Analysis station (NAA) [22].

\section{Materials}

This work focuses on the analysis of the isotope inventory of SINQ Target 4 (Mark III), which had been operated in 2000-2001 for an integral time of 16 months. Within two irradiation periods a total proton charge of 10.03 Ah was deposited inside the 350 lead rods. Each of them had a length of $110 \mathrm{~mm}$ and a diameter of $10.8 \mathrm{~mm}$ and contained about $80 \mathrm{~g}$ of lead. The composition of typical lead used for SINQ targets was analysed with inductively coupled plasma optical emission spectrometry (ICP-OES). Impurities of Bi and $\mathrm{Sb}$ were identified. Results are presented in Table 1. Matrix effects and measurements close to the determination limits of the elements cause large uncertainties. For all other elements values below their determination limit were measured.

In 2006, after 5 years of cooling time, one rod designated as "Rod 3" has been selected for examination of the target system, due to its central position near the beam entry (see Fig. 1). In Fig. 2, the results of calculations of the longitudinal distribution of proton and neutron doses for this rod are presented. The values are extrapolations of MCNPX calculations of close positions of this target [18] and comparable positions of target 6 (STIP-IV).

According to the intensity profile of the beam the proton dose in the centre region of this rod is about 10 times higher than in the edge region. This also caused a large gra-

Table 1. Impurities found in inactive $\mathrm{Pb}$ with ICP-OES (averaged values of 3 samples).

$\mathrm{Bi}$ $\mathrm{Sb}$

Concentration $(\mu \mathrm{g} / \mathrm{g} \mathrm{Pb})$

$136.14 \pm 19.71$

$65.29 \pm 2.05$ 


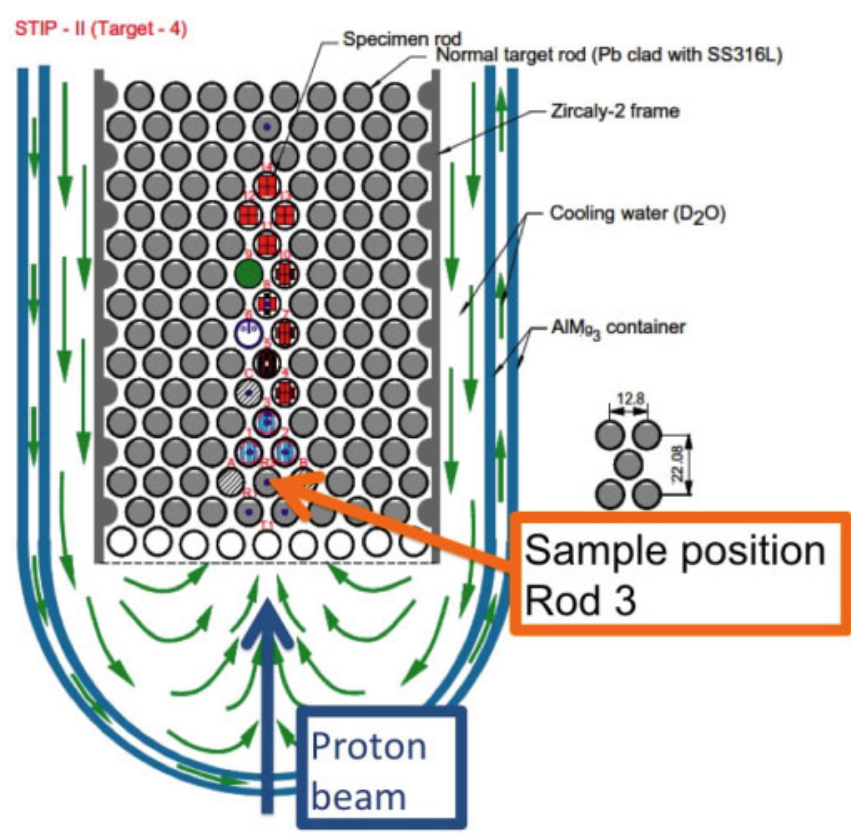

Fig. 1. Scheme of SINQ target 4 , Rod 3 is indicated (picture taken from [18]).

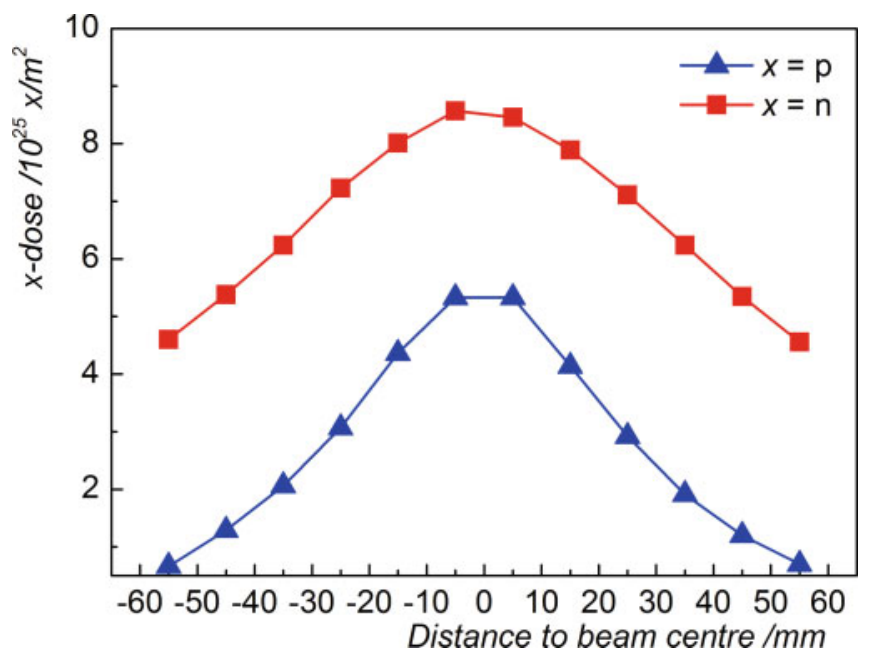

Fig. 2. Longitudinal distributions of proton dose (p) and neutron dose (n) for Rod 3 of SINQ target 4.

dient distribution of the neutron dose and of the temperature. After extraction, Rod 3 was cut into several discs (Fig. 3). These discs shall represent samples with different levels of applied proton and neutron dose and consequently varying production rates of isotopes.

In 2011, after 10 years of cooling time, the samples of the positions D3 (1.5 mm from beam axis), D9 (25 mm), D10 (27 mm), D12 (47 mm), and D14 (49 mm) (see Fig. 3) were cut into small pieces of about 10 to $80 \mathrm{mg}$, each. Thereby, the steel cladding containing large amounts of ${ }^{60} \mathrm{Co}$ could be removed, which considerably decreased the dose rates of the samples. For discs D3, D10, and D12, pieces from the inner and outer part of the disc were taken, in order to examine possible concentration gradients of the radionuclides across the diameter of the rod. The cutting was done manually with tweezers and side cutter behind a $5 \mathrm{~cm}$ thick lead shielding. The obtained pieces had dose rates between 50 and $500 \mu \mathrm{Sv} / \mathrm{h}$ at a few centimetres distance.

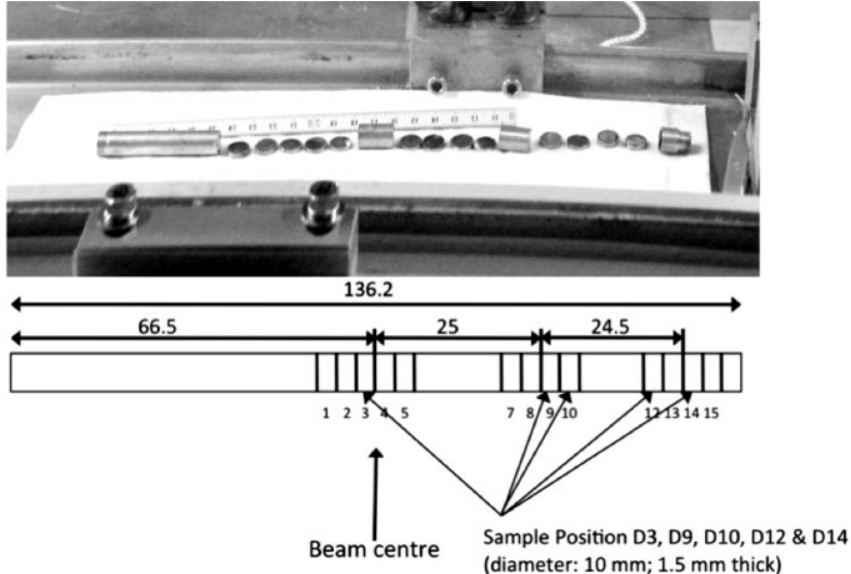

Fig. 3. Photography and scheme: sawing the lead rod discs (dimensions in $\mathrm{mm}$ ).

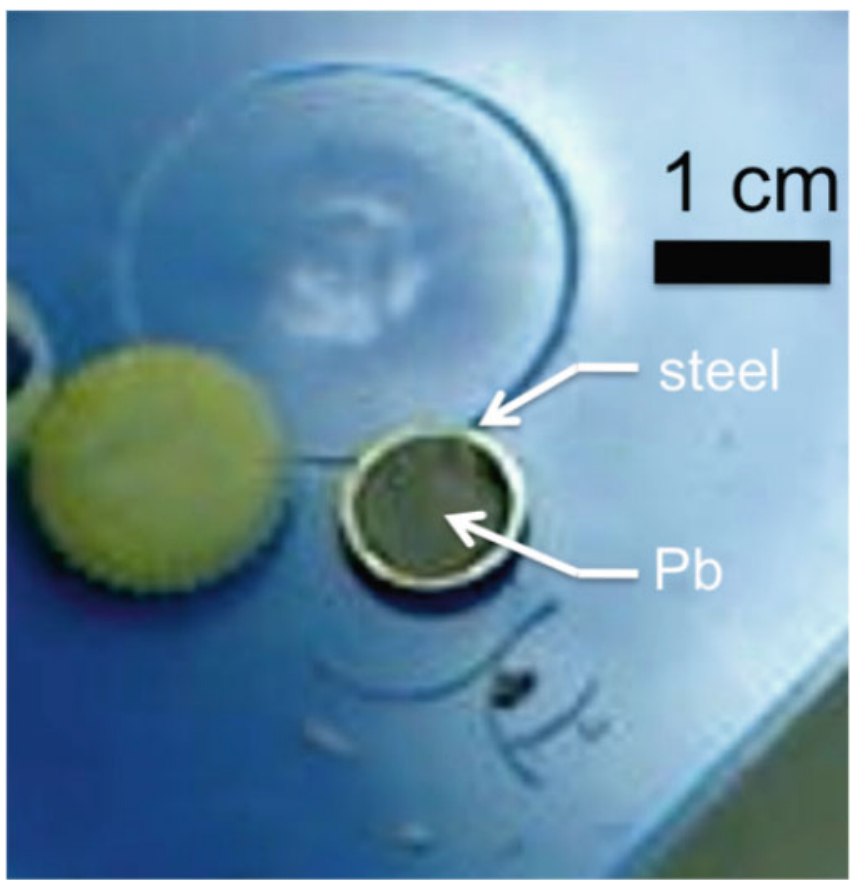

Fig. 4. Photography of a lead disc with steel cladding from Rod 3 of SINQ Target 4.

\section{Results and discussion}

A detailed $\gamma$-analysis was performed using an HPGe detection system of Canberra and GENIE2000 software. Three to four lead pieces of each disc (see Figs. 3-5) were measured for 4 to $12 \mathrm{~h}$. The $\gamma$-spectra (see Fig. 6) are very complex and contain more than 160 single peaks and multiplets. With this non-destructive technique the isotopes ${ }^{207} \mathrm{Bi}$, ${ }^{194} \mathrm{Hg} /{ }^{194} \mathrm{Au},{ }^{173} \mathrm{Lu},{ }^{172} \mathrm{Hf} /{ }^{172} \mathrm{Lu},{ }^{133} \mathrm{Ba},{ }^{125} \mathrm{Sb},{ }^{102 \mathrm{~m}} \mathrm{Rh},{ }^{101} \mathrm{Rh}$ and ${ }^{60} \mathrm{Co}$ were identified as main nuclides.

Some isotopes, like ${ }^{108 \mathrm{~m}} \mathrm{Ag},{ }^{44} \mathrm{Ti} /{ }^{44} \mathrm{Sc}$ and ${ }^{202} \mathrm{~Pb} /{ }^{202} \mathrm{Tl}$, with only a single $\gamma$-line or with $\gamma$-energies less than $100 \mathrm{keV}$ were not considered for evaluation, due to large uncertainties caused by the large Compton-background, self absorption or peak overlap. For example, ${ }^{44} \mathrm{Ti}$ can be usually determined by the strong $1157 \mathrm{keV} \gamma$-peak emitted by the daughter nuclide ${ }^{44} \mathrm{Sc}$. As shown in Fig. 7, this peak overlaps with a weak $\gamma$-line of ${ }^{194} \mathrm{Au}$. The results of the interference 


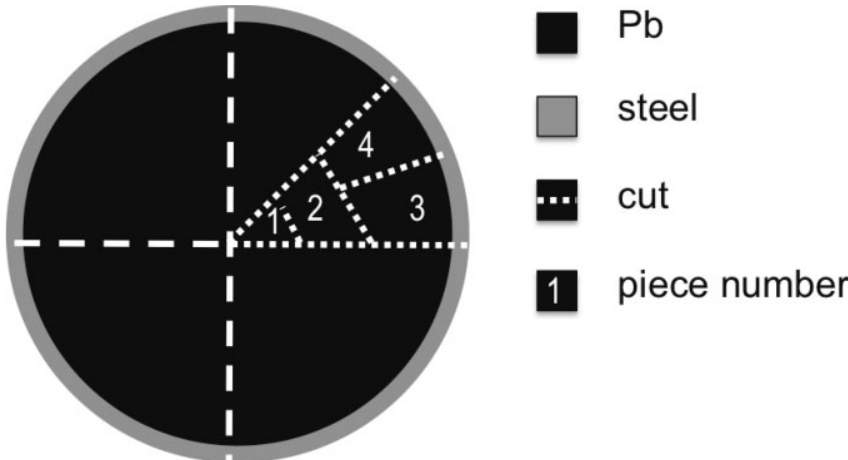

Fig. 5. Example of the disc cutting: pieces $1 \& 2$ from the inner part, pieces $3 \& 4$ from the outer part of the lead disc.

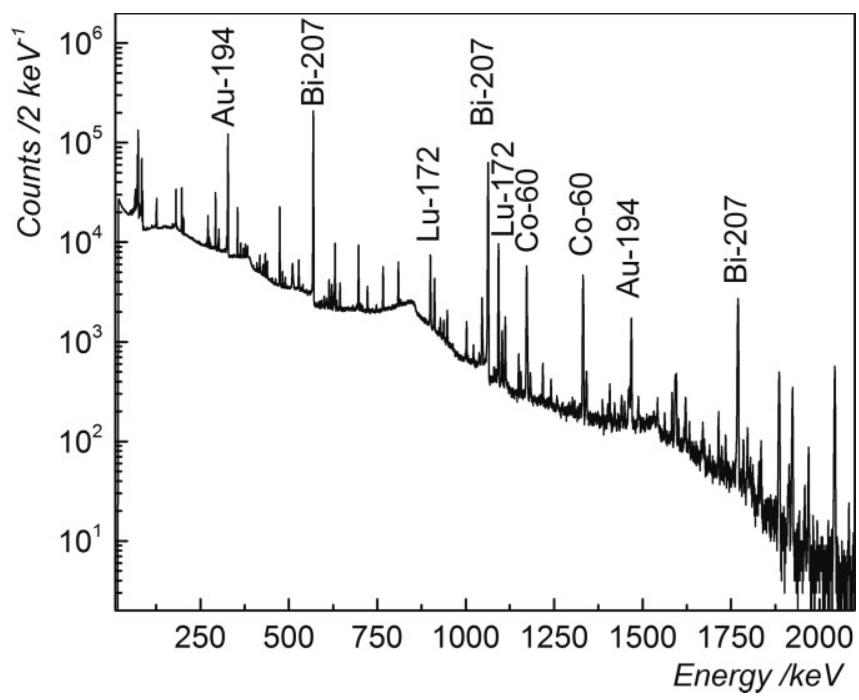

Fig. 6. Typical $\gamma$-spectrum with several main isotopes indicated.

deconvolution were not satisfying. Hence, chemical techniques have to be applied in order to separate interfering nuclides. Several examples to separate ${ }^{44} \mathrm{Ti} /{ }^{44} \mathrm{Sc}$ from radioactive waste are described in literature [10,23,24]. This task will be faced in future work.

The evaluated and averaged activities for the selected radionuclides are presented in Fig. 8. All values were normalized to end of beam (EOB, 23 December 2001).

As expected, the highest activities are observed in the region of the beam centre. The values are decreasing in direction to the end of the rod. The profile of the isotope concentration is in good agreement with the profile of the proton flux (see Fig. 8).

Within a single sample no evident gradients from the inner to the outer part of the lead disc were found. The uncertainties

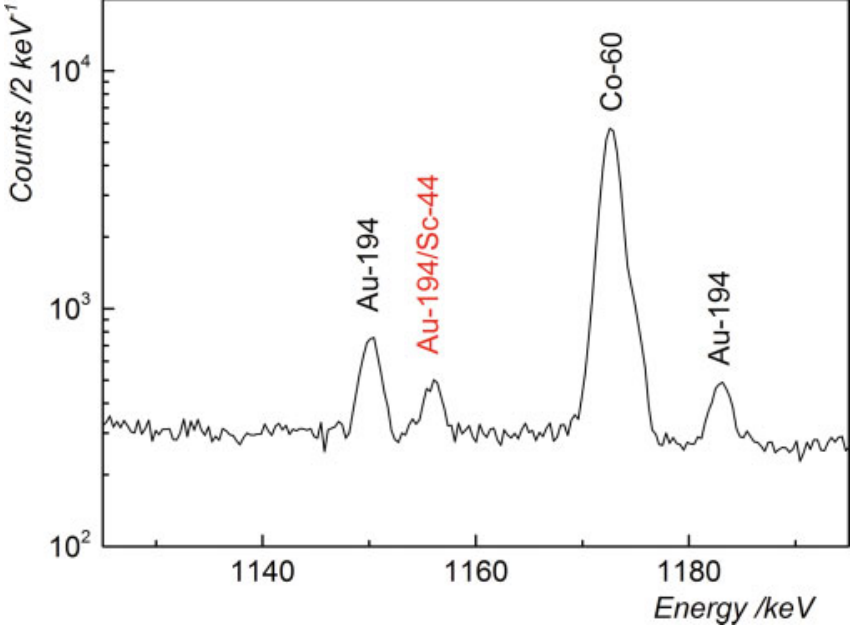

Fig. 7. Overlapping peak of ${ }^{194} \mathrm{Au}$ and ${ }^{44} \mathrm{Sc}$ at $1157 \mathrm{keV}$.

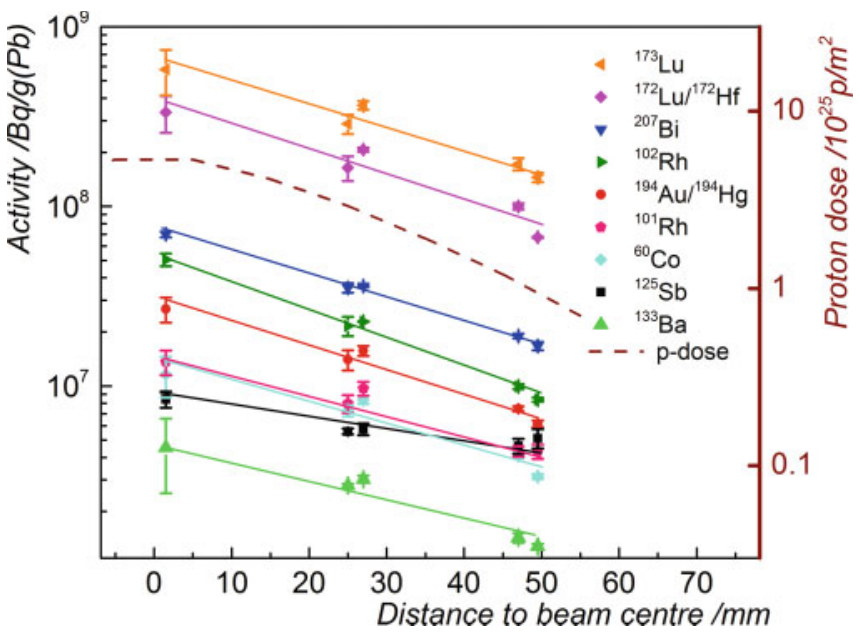

Fig. 8. Averaged activities of selected radionuclides (normalized to EOB) determined by $\gamma$-spectroscopy (the error bars indicate the standard deviation), the lines only indicate a trend for illustration and no regression; the corresponding proton dose (calculated with MCNPX) is indicated as dashed line.

of the averaged values of the species $\mathrm{Lu}, \mathrm{Ba}$, and $\mathrm{Co}$, indicated by the error bars, strongly increase towards the beam centre. Online temperature measurements during irradiation revealed an average value of $550 \pm 30 \mathrm{~K}$ in the middle of this rod. This average value is only slightly below the melting point of lead at $600.6 \mathrm{~K}$. Hence, a partly melting of lead in the central region becomes possible, due to temperature peaks, certainly occurring several times during such a long irradiation period. Ignoble elements easily form oxidic compounds with present traces of oxygen. Their surface segre-

Table 2. Number of produced atoms per gram of lead of selected radionuclides at EOB in sample D03.

\begin{tabular}{llll}
\hline Sample D03 & Number of atoms/g $(\mathrm{Pb})$ & & \multicolumn{1}{c}{ Number of atoms/g $(\mathrm{Pb})$} \\
\hline Produced by & evaporation of $x$ pyn & Produced by high-energy fission \\
${ }^{207} \mathrm{Bi}$ & $1.00 \times 10^{17} \pm 3.7 \%$ & ${ }^{102 \mathrm{~m}} \mathrm{Rh}$ & $1.30 \times 10^{15} \pm 8.2 \%$ \\
${ }^{194} \mathrm{Hg} /{ }^{194} \mathrm{Au}$ & $5.60 \times 10^{17} \pm 16 \%$ & ${ }^{101} \mathrm{Rh}$ & $2.04 \times 10^{15} \pm 15.7 \%$ \\
${ }^{172} \mathrm{Hf} /{ }^{172} \mathrm{Lu}$ & $2.80 \times 10^{16} \pm 23.2 \%$ & ${ }^{60} \mathrm{Co}$ & $2.80 \times 10^{15} \pm 25.6 \%$ \\
${ }^{173} \mathrm{Lu}$ & $3.50 \times 10^{16} \pm 28.4 \%$ & ${ }^{125} \mathrm{Sb}$ & $1.10 \times 10^{15} \pm 10.3 \%$ \\
& & ${ }^{133} \mathrm{Ba}$ & $2.20 \times 10^{15} \pm 44.5 \%$ \\
\hline
\end{tabular}


gation and agglomeration on the liquid lead phase due to the limited solubility in lead compared to, e.g., noble elements explains the variance in the measured concentrations in this part of the rod. Indeed, more soluble species like $\mathrm{Bi}, \mathrm{Rh}$, and Sb show a much smaller variance. The comparison of the radionuclide concentration (see Table 2) shows coherence of the amounts related to the individual production mechanism. Concentrations of species produced by high-energy fission (e.g. ${ }^{102 \mathrm{~m}} \mathrm{Rh},{ }^{101} \mathrm{Rh},{ }^{125} \mathrm{Sb},{ }^{133} \mathrm{Ba},{ }^{60} \mathrm{Co}$ ) range in the same order of magnitude, about $10^{15}$ atoms per gram of lead. Isotopes produced by neutron-proton evaporation $\left({ }^{194} \mathrm{Hg} /{ }^{194} \mathrm{Au},{ }^{207} \mathrm{Bi}\right)$ reach a value of $10^{17}$ atoms per gram of lead.

\section{Conclusion}

In this work, first results of an extensive investigation on the radionuclide inventory in a single lead rod of SINQ Target 4 and its radial distribution with respect to the beam axis has been presented. A detailed $\gamma$-analysis of samples with different distances to the beam axis was performed. For the selected radionuclides ${ }^{207} \mathrm{Bi},{ }^{194} \mathrm{Hg} /{ }^{194} \mathrm{Au},{ }^{173} \mathrm{Lu},{ }^{172} \mathrm{Hf} /{ }^{172} \mathrm{Lu}$, ${ }^{133} \mathrm{Ba},{ }^{125} \mathrm{Sb},{ }^{102 \mathrm{~m}} \mathrm{Rh},{ }^{101} \mathrm{Rh}$ and ${ }^{60} \mathrm{Co}$, a radial distribution at the level of beam entry was shown. It was demonstrated, that the intensity of proton flux is directly affecting the nuclide distribution. A comparably high concentration variance of the ignoble elements $\mathrm{Lu}, \mathrm{Ba}$, and $\mathrm{Co}$ in the sample of the central region D3 of this rod, which may have temperatures above $600 \mathrm{~K}$ during irradiation, has been observed. Presumably, chemical reaction, compound segregation, and agglomeration processes, due to the liquid state of lead, are causing this effect.

\section{Outlook}

The here presented work covers only the determination of radionuclides, which can be measured without destruction of the sample. However, some of the safety-relevant isotopes and the interesting ones for the ERAWAST project are not so easily detectable. Due to the low range of $\alpha$ particles in solid matter, the determination of $\alpha$-emitters like ${ }^{208-210} \mathrm{Po}$ or ${ }^{148} \mathrm{Gd}$ requires a chemical separation of the specific element from the matrix material. The measurements of these nuclides can afterwards be carried out with $\alpha$-spectrometry using a high quality thin-sample. For isotopes with very long half-lives ( $>10^{6}$ years) like ${ }^{36} \mathrm{Cl},{ }^{129} \mathrm{I}$, ${ }^{182} \mathrm{Hf}$ and others, counting of atoms using mass spectroscopic methods is more effective than counting the decay by conventional radiation measurements, and especially in cases where the radiation properties do not allow a direct measurement, Accelerator Mass Spectrometry (AMS) or Inductive Coupled Plasma-Mass Spectrometry (ICP-MS) are the methods of choice. However, a very time consuming and high sophisticated sample preparation for these isotopes is required. A dedicated radiochemical separation procedure for every desired radionuclide from the matrix material has to be developed. The isolation of micro amounts of these nuclides, around $10^{12}$ to $10^{17}$ atoms per gram of lead represents a challenging task.

In order to get information on the distribution of the radionuclides in beam direction, the complete analytics has also to be repeated done for samples of other positions in the SINQ, which is foreseen within the next 2 years with 2-3 additional rods from SINQ target 4.

Acknowledgment. This work is funded by the Swiss National Science Foundation (SNSF). Acknowledgement to S. Köchli (PSI) for performing ICP-OES measurements on lead. Thanks to R. Dressler, A. Vögele, H. P. Linder and R. Eichler (PSI) for support.

\section{References}

1. Bauer, G. S., Fischer, W. E., Rohrer, U., Schryber, U.: Commissioning of the $1 \mathrm{MW}$ spallation neutron source SINQ. Proc. Part. Accel. Conf. 3 (1997)

2. Bauer, G. S., Dai, Y., Wagner, W.: SINQ layout, operation, applications and R\&D to high power. J. Phys. IV 12, 3 (2012)

3. Filges, D., Goldenbaum F: Handbook of Spallation Research: Theory, Experiments and Applications. $1^{\text {st }}$ Edn., Wiley-VCH Verlag $\mathrm{GmbH} \& \mathrm{Co} . \mathrm{KGaA}$ (2009).

4. Miller, C. W., Whitcomb, R. C., Ansari, A., McCurley, C., Nemhauser, J. B., Jones, R.: Murder by radiation poisoning: implications for public health. J. Environ. Health 74, 8 (2012).

5. Artisyuk, V., Saito, M., Stankovskii, A., Korovin, Y., Shmelev, A.: Radiological hazard of long-lived spallation products in accelerator-driven system. Prog. Nucl. Energy 40, 637 (2002).

6. Neuhausen, J., Eichler, B.: Investigations on the thermal release of iodine from liquid eutectic lead-bismuth alloy. Radiochim. Acta 94, 239 (2006)

7. Neuhausen, J.: Investigations on the release of mercury from liquid eutectic lead-bismuth alloy under different gas atmospheres. Nucl. Instrum. Methods A 562, 702 (2006).

8. Neuhausen, J., Köster, U., Eichler, B.: Investigation of evaporation characteristics of polonium and its lighter homologues selenium and tellurium from liquid $\mathrm{Pb}-\mathrm{Bi}$-eutecticum. Radiochim. Acta 92, 917 (2004).

9. Schumann, D., Neuhausen, J.: Accelerator waste as a source for exotic radionuclides. J. Phys. G 35, 014046 (2008).

10. Dressler, R., Ayranov, M., Bemmerer, D., Bunka, M., Dai, Y., Lederer, C., Fallis, J., Murphy, A. S., Pignatari, M., Schumann, D., Stora, T., Stowasser, T., Thielemann, F.-K., Woods, P. J.: ${ }^{44} \mathrm{Ti},{ }^{26} \mathrm{Al}$ and ${ }^{53} \mathrm{Mn}$ samples for nuclear astrophysics: the needs, the possibilities and the sources. J. Phys. G 39, 105201 (2012).

11. Rugel, G., Faestermann, T., Knie, K., Korschinek, G., Poutivtsev, M., Schumann, D., Kivel, N., Günther-Leopold, I., Weinreich, R., Wohlmuther, M.: New measurement of the ${ }^{60} \mathrm{Fe}$ halflife. Phys. Rev. Lett. 103, 072502 (2009).

12. Uberseder, E., Reifarth, R., Schumann, D., Dillmann, I., Pardo, C. D., Görres, J., Heil, M., Käppeler, F., Marganiec, J., Neuhausen, J., Pignatari, M., Voss, F., Walter, S., Wiescher, M.: Measurement of the ${ }^{60} \mathrm{Fe}(n, \gamma){ }^{61} \mathrm{Fe}$ cross section at stellar temperatures. Phys. Rev. Lett. 102, 151101 (2009).

13. Meulders, J. P., Koning, A., Leray, S.: High and intermediate energy nuclear data for accelerator-driven systems. Hindas Final Report, FIS5-00150 (2005).

14. Aït Abderrahim, H., Baeten, P., De Bruyn, D., Fernandez, R.: MYRRHA - a multi-purpose fast spectrum research reactor. Energy Convers. Manage. 63, 4 (2012).

15. Dai, Y., Bauer, G. S.: Status of the first SINQ irradiation experiment, STIP-I. J. Nucl. Mater. 296, 43 (2001).

16. Dai, Y., Fazio, C., Knebel, J. U., Groschel, F.: Discussion on the lifetime of the target based on preliminary STIP results. In: Proceedings of the $4^{\text {th }}$ Megapie Technical Review Meeting, Forschungszentrum Karlsruhe Technik \& Umwelt, Karlsruhe (2003), pp. 172-183.

17. Wagner, W., Dai, Y., Glasbrenner, H., Grosse, M., Lehmann E: Status of SINQ, the only MW spallation neutron source - highlighting target development and industrial applications. Nucl. Instrum. Methods A 562, 541 (2006).

18. Dai, Y., Jia, X., Thermer, R., Hamaguchi, D., Geissmann, K., Lehmann, E., Linder, H. P., James, M., Gröschel, F., Wagner, W., Bauer, G. S.: The second SINQ target irradiation program, STIPII. J. Nucl. Mater. 343, 33 (2005). 
19. Bauer, G. S., Salvatores, M., Heusener, G.: MEGAPIE, a 1 MW pilot experiment for a liquid metal spallation target. J. Nucl. Mater. 296, 17 (2001).

20. Wagner, W., Vontobel, P., Dai, Y.: Materials issues of the SINQ high-power spallation target. Int. J. Mater. Res. 102, 1101 (2011).

21. Thomsen, K., Heinrich, F., Butzek, M., Wolters, J., Sordo, F., Holm, A. I. S.: Some technical issues for a cannelloni spallationtarget at high power. Nucl. Instrum. Methods A 682, 42 (2012).
22. Wagner, W.: The SINQ solid spallation target - operational experience and recent improvements. High Power Targetry Workshop, Malmö (2011).

23. Schumann, D., Ayranov, M.: Preparation of ${ }^{60} \mathrm{Fe},{ }^{7} \mathrm{Be},{ }^{44} \mathrm{Ti}$ and other samples for nuclear physics experiments. J. Phys., Conf. Ser. (UK) 202, 012034 (2010).

24. Ayranov, M., Schumann, D.: Preparation of ${ }^{26} \mathrm{Al},{ }^{59} \mathrm{Ni},{ }^{44} \mathrm{Ti},{ }^{53} \mathrm{Mn}$ and ${ }^{60} \mathrm{Fe}$ from a proton irradiated copper beam dump. J. Radioanal. Nucl. Chem. 286, 649 (2010). 